Methods In a controlled, prospective, comparative two-arm study we treated 105 patients with established CIO (average age 65 years) over three years with either $2 \mathrm{mg}$ ibandronate every 3 months iv (group A) or with a daily dose of $1 \mathrm{mg}$ alfacalcidol orally (group B). All patients received a $500 \mathrm{mg}$ calcium supplement per day. The patients had been on CS for an average time of 8 years. The initial mean BMD values were very low (T-score lumbar spine -3.8 , femoral neck -3.1). $91 \%$ of the patients had 1 or more prevalent vertebral fractures (average: 3.8 fractures/ patient).

Results During the 36 months of observation there was a progressive reduction in back pain in both groups. No relevant adverse events were recorded. Mean BMD at the lumbar spine increased by $14.2 \%$ in the ibandronate cases and $2.3 \%$ in the 1 alpha group $(\mathrm{p}<0.0001)$. The corresponding changes after 3 years for the femoral neck were 5.1\% and 1.6\% ( $p=0.0005)$. Six new vertebral fractures per 6 patients were observed in group $\mathrm{A}$ and 15 per 12 patients in group $\mathrm{B}$.

Conclusion We conclude that ibandronate is superior to alfacalcidol in the treatment of CIO. The data confirm the very positive effect of BP therapy on the course of CIO. The very good acceptance and excellent compliance with the 3 months bolus therapy in our trial, the scarcity of adverse events and the avoidance of poor intestinal absorption make ibandronate a very interesting alternative to oral BP treatment.

\section{OP0112 NONSPINE FRACTURES ARE ASSOCIATED WITH PHYSICAL IMPAIRMENT}

${ }^{1} \mathrm{PD}$ Ross, ${ }^{2} \mathrm{JW}$ Davis, ${ }^{3} \mathrm{~J}$ Chandler, ${ }^{2} \mathrm{RD}$ Wasnich. ${ }^{1}$ Scientific Communications Group, Merck \& Co., Inc., Rahway; ${ }^{2}$ Epidemiology, Hawaii Osteoporosis Center, Honolulu; ${ }^{3}$ Epidemiology, Merck \& Co., Inc., Blue Bell, USA

\subsection{6/annrheumdis-2001.633}

Background There have been few studies of physical impairment following nonspine fractures.

Objectives To examine this issue among 705 Japanese women in Hawaii.

Methods Only new fractures that had occurred during 13 years of follow up were considered; 121 women had 1, and 26 women had 2 or more new nonviolent, nonspine fractures. Activities of daily living (ADLs) and measures of physical performance (PP) were measured at the end of follow up. Associations with new nonspine fractures were evaluated using logistic regression analysis adjusted for age, height, body mass index, prior vertebral fractures, and prior nonspine fractures.

Results Women with new fractures had significantly greater difficulty with 10 out of 13 ADLs, with odds ratios of 1.6 to 2.9. The associations tended to be stronger for fractures within the prior 5 years; only 2 ADLs were significantly associated with fractures that had occurred more than 5 years earlier. For most ADLs, associations with hip, rib, and upper arm fractures were generally stronger (odd ratios $>2.3$ ) than for wrist, foot, or lower leg fractures (odds ratios $<2.0$ ). Overall, nonspine fractures were significantly associated with $25 \%$ slower walking speed and longer time to complete the chair stand test, but not with other PP measures. However, hip fractures were associated with lower performance on 5 out of 6 PPs.

Conclusion We conclude that nonspine fractures may be associated with increased physical impairment for up to 5 years later, and that the severity appears to vary by fracture location.

\section{OP0113 INCREASES IN BONE MINERAL DENSITY EXPLAIN THE REDUCTION IN INCIDENCE OF NONVERTEBRAL FRACTURES SEEN WITH ANTIRESORPTIVE THERAPY IN WOMEN WITH POSTMENOPAUSAL OSTEOPOROSIS}

${ }^{1} \mathrm{RD}$ Wasnich, ${ }^{2} \mathrm{MC}$ Hochberg, ${ }^{3} \mathrm{~S}$ Greenspan, ${ }^{4} \mathrm{PD}$ Ross, ${ }^{5} \mathrm{PD}$ Miller. ${ }^{1}$ Research Department, Hawaii Osteoporosis Center, Honolulu; ${ }^{2}$ Epidemiology, University of Maryland, Baltimore; ${ }^{3}$ Department Medicine, University of Pittsburgh, Pittsburgh; ${ }^{4}$ Scientific Communications, Merck \& Co., Inc., Rahway; ${ }^{5}$ Research Department, Colorado Center for Bone Research, Lakewood, USA

\subsection{6/annrheumdis-2001.634}

Background A recently published meta-analysis of randomised, placebo-controlled trials of antiresorptive agents in postmenopausal women found a significant relationship between increases in bone mineral density (BMD) and reductions in risk of radiographic vertebral fractures, as well as a small risk reduction not explained by change in BMD. ${ }^{1}$ It is unknown, however, whether a similar relationship exists between increases in BMD and a reduction in risk of clinical nonvertebral fractures.

Objectives To examine the extent to which increases in BMD during antiresorptive therapy are associated with reductions in risk of nonvertebral fractures.

Methods We performed a meta-analysis of all randomised, placebo-controlled trials of antiresorptive agents conducted in postmenopausal women with osteoporosis with available relevant data. A total of 15 such trials with usable data were identified including a total of 1911 women with incident nonvertebral fractures over 54,952 women-years of follow up. Poisson regression was used to estimate the association between increase in $\mathrm{BMD}$ (change in the treatment group - change in placebo group) and relative risk (RR) of nonvertebral fractures across all trials; separate models were constructed for change in spine BMD and change in hip BMD.

Results Both models found a significant relationship between increases in BMD and reductions in nonvertebral fracture risk. For each 1 percent increase in bone mineral density at the lumbar spine, there was a 4.3 percent decrease in risk of nonvertebral fracture $(P=0.029)$; for each 1 percent increase in bone mineral density at the hip, there was a 8.8 percent decrease in risk of nonvertebral fracture $(\mathrm{P}=0.016)$. In neither model was there a significant decrease in risk of nonvertebral fractures in the absence of increase in bone mineral density. Thus, an agent that increases spine BMD by $8 \%$ reduces nonvertebral fracture risk by about $40 \%$, and an agent that increases hip BMD by $5 \%$ also reduces nonvertebral fracture risk by about $40 \%$.

Conclusion These data demonstrate that larger increases in BMD at both the spine and hip are associated with greater reductions in risk of nonvertebral fractures. Antiresorptive agents which do not produce large increases in BMD do not appear to and would not be expected to decrease the risk of nonvertebral fractures.

\section{REFERENCE}

1 J Clin Endocrinol Metab. 2000:85:231-6 